\title{
NINJAS FAZEM BICO? UM ESTUDO DE PLATAFORMA DE CROWDSOURCING NO BRASIL
}

\section{DO NINJAS GIG? A CROWDSOURCING PLATFORM STUDY IN BRAZIL}

\author{
RODRIGO DE LACERDA CARELLI ${ }^{1}$ \\ ANGELA TAVARES DE CASTRO BITTENCOURT ${ }^{2}$
}

RESUMO: O presente trabalho realiza uma análise sobre a plataforma de crowdsourcing GetNinjas. Baseado em pesquisa empírica, por meio de questionário semiestruturado apresentado a vinte e quatro trabalhadores inscritos na plataforma, que se voluntariaram a responder às perguntas on-line em formulário eletrônico disponibilizado, o artigo conclui que o objeto de pesquisa pode ser definido como uma plataforma de crowdsourcing mista e genérica que atua tanto em nível global (on-line) quanto em nível local (off-line). O estudo, além de apontar problemas relacionados com a concorrência entre trabalhadores, em uma espécie de leilão negativo, e com a avaliação unilateral publicizada dos prestadores de serviços por parte dos clientes, sem a existência de um contraditório antes da qualificação, argumenta que a cobrança de "moedas virtuais" realizada pela empresa para os profissionais acessarem as propostas de trabalho não é lícita, tendo em vista o princípio da não-mercantilização do trabalho, a Convenção no 181 da OIT (Organização Internacional do Trabalho) e a aplicação analógica da Lei $\mathrm{n}^{\mathrm{o}}$ $6.019 / 1974$.

PalavRas-Chave: Trabalho por meio de plataformas digitais; Economia do bico; Princípio da não-mercantilização do trabalho.

\footnotetext{
${ }^{1}$ Professor de Direito do Trabalho e do Programa de Pós-Graduação em Direito da Universidade Federal do Rio de Janeiro (UFRJ). Doutor em Ciências Humanas (Sociologia) pelo IESP/UERJ. Doutor em Direito e Sociologia pela UFFCV: http://lattes.cnpq.br/6162675542648709. Contato: rodrigolcarelli@gmail.com.

${ }^{2}$ Mestranda em Políticas Públicas em Direitos Humanos pelo Núcleo de Estudos em Políticas Públicas em Direitos Humanos da Universidade Federal do Rio de Janeiro (NEPP-DH/UFRJ). Membro do Grupo de Pesquisa "Trabalho no Século XXI" da Universidade Federal do Rio de Janeiro (UFRJ). Contato: angelatcb@gmail.com. CV Lattes: http://lattes.cnpq.br/9315602096007677.
} 
ABSTRACT: This work undertakes the study on the GetNinjas crowdsourcing platform. Based on empirical research, by means of a semi-structured questionnaire presented to twenty-four workers enrolled in the platform, who volunteered to answer the questions online in the electronic form provided, the article verifies that the object of the study is a mixed and generic crowdsourcing platform, and that it operates at both the global level (online) and the local level (offline). The study, in addition to pointing out problems related to competition among workers, in a kind of negative auction, and to the unilateral assessment of service providers published by clients, without the existence of a contradictory before qualification, argues that the charging of "virtual currencies" by the company for professionals to access the work proposals is not lawful, in view of the principle of decommodification of labour, ILO Convention No. 181 (International Labor Organization) and the analogical application of Law No. 6,019/1974.

KEYWORDS: Platform work; Gig Economy; ILO's principle of decommodification of labour.

\section{INTRODUÇÃO}

As tecnologias digitais implementadas na segunda década do século XXI, possibilitadas pelo avanço da internet móvel e pela disseminação dos aparelhos celulares ditos smartphones, permitiram que empresas criassem plataformas para a oferta em larga escala de trabalhadores para a prestação de serviços, dando origem a fenômenos como gig economy ("economia do bico"), capitalismo de plataforma, crowdsourcing e on-demand economy ("economia por demanda") (ALOISI, 2016; IVANOVA et al., 2018; OLIVEIRA, 2019).

Como se observa, para descrever fenômenos bastante semelhantes há referências a inúmeras terminologias, não havendo uniformidade para denominar o trabalho estudado. Todas essas denominações têm uma razão por trás: a contratação de trabalhadores por tarefas e por curtíssimo período de tempo transforma o trabalho em mero "bico", sem condições de se tornar uma profissão ou seguir uma carreira, daí o uso da expressão "economia do bico" (ABÍLIO, 2019); capitalismo de plataforma pode ser uma terminologia válida, pois as relações jurídicas, inclusive as de trabalho, vêm sendo intermediadas constantemente por uma plataforma digital (KALIL, 2019); a busca de trabalhadores em uma plataforma permite que o fornecimento da mão de obra seja realizado por uma multidão mobilizada de forma total a prestar serviços a quem possa interessar, gerando o que se chama de crowdsourcing (TODOLÍ, 2017); e a contratação de trabalhadores em plataformas se dá a partir de uma demanda específica do tomador de serviços, e somente vale para aquele chamado, não havendo pretensão, 
ao menos por parte do tomador, de qualquer continuidade na relação laboral, possibilitando a denominação "economia por demanda" (DANIGNO, 2016).

Entre as denominações usuais, no entanto, deve-se evitar a terminologia "economia de compartilhamento", pois é enganosa, porque o que se negocia no fundo são seres humanos que trabalham, que se "auto compartilham" com os tomadores de serviços, além de poder gerar uma conotação positiva à mera precarização das condições de trabalho (CARELLI; CASAGRANDE; OITAVEN, 2018).

No presente trabalho pretende-se analisar o fenômeno das plataformas digitais em sua vertente de trabalho por crowdsourcing, no contexto da chamada gig economy ou "economia por demanda", por meio do estudo de caso da plataforma de trabalho denominada GetNinjas. A escolha dessa plataforma ocorreu pelo fato de que ela se autointitula "a maior plataforma de contratação de serviços do Brasil"3.

$\mathrm{O}$ estudo tem como base a apresentação do estado da arte da literatura sobre plataformas de trabalho para verificar a natureza da plataforma que ora se estuda; a busca de elementos disponíveis no site da empresa, com o objetivo de elucidar qual seria o seu modo de funcionamento; e a realização de estudo empírico por meio de questionário semiestruturado apresentado a vinte e quatro trabalhadores inscritos na plataforma, que se voluntariaram a responder às perguntas on-line em formulário eletrônico disponibilizado.

Os trabalhadores convidados foram escolhidos de forma aleatória a partir dos contatos disponíveis de forma aberta na própria plataforma. $\mathrm{O}$ participante teve a liberdade de não responder quaisquer das perguntas, disponibilizadas por meio do Formulários Google, e as informações são utilizadas na presente investigação acadêmica de forma anônima/sigilosa. As entrevistas foram realizadas ao longo do segundo semestre de 2019.

O objetivo do presente estudo é, a partir das características levantadas na parte empírica, identificar o tipo de plataforma e a espécie de relação de trabalho estabelecida entre plataforma e trabalhadores e verificar a legalidade do modus operandi da plataforma.

Para isso, na primeira seção serão apresentados os dados levantados sobre a plataforma. A segunda seção examinará o tipo de plataforma ao qual a empresa pode ser identificada. E na terceira será analisada juridicamente a operação da plataforma.

\footnotetext{
${ }^{3}$ Conforme informação disponibilizada em seu site https://www.getninjas.com.br/. Acesso em: 07 jan. 2020. Não há como confirmar essa informação unilateral da empresa, pois não há até a presente data estudo comparativo levantando os números das plataformas no Brasil. Entretanto, realmente a plataforma é a mais conhecida no gênero no país.
} 
O presente estudo é parte da pesquisa levada a cabo no Grupo de Pesquisa Trab21 - Trabalho no Século XXI, vinculado ao Programa de Pós-Graduação em Direito da Universidade Federal do Rio de Janeiro. ${ }^{4}$

\section{A PLATAFORMA GETNINJAS: O SEU MODO DE FUNCIONAMENTO E O PERFIL DOS TRABALHADORES}

\subsection{O modus operandi da plataforma}

A plataforma GetNinjas, cuja atuação é de âmbito nacional, é disponibilizada diretamente na Internet a partir de um computador, no site www.getninjas.com.br, ou por meio de aplicativo disponível para aparelhos celulares que funcionam com os sistemas operacionais Android ou iOS. Pelos mesmos canais pode-se acessar como profissional ou como tomador de serviços.

Para trabalhar por intermédio da plataforma o profissional deve se cadastrar apontando a região e o serviço que deseja prestar, além de concordar com uma espécie de contrato denominado pela empresa de "Termos de Uso" (GETNINJAS, 2020). Esse documento é unilateralmente produzido pela plataforma, e a ele adere obrigatoriamente o prestador do serviço, que fica à mercê de quaisquer mudanças promovidas por GetNinjas, que sequer se obriga a avisá-lo sobre eventuais mudanças em sua redação. Confira-se:

4.1 GetNinjas poderá alterar, a qualquer tempo e a seu único e exclusivo critério, estes Termos. Os novos Termos entrarão em vigor 10 (dez) dias depois de publicados na Plataforma. No prazo de 5 (cinco) dias contados a partir da publicação das modificações, o Usuário deverá informar, por e-mail, caso não concorde com os termos alterados. Nesse caso, o vínculo contratual deixará de existir, desde que não haja contas ou dívidas em aberto. Não havendo manifestação no prazo estipulado, entender-se-á que o Usuário aceitou tacitamente os novos Termos, e o contrato continuará vinculando as partes. (grifos não constantes do original).

$\mathrm{Na}$ abertura do aplicativo a empresa apresenta como seu objetivo conectar "clientes com os melhores profissionais". Para isso, ao se cadastrar no site ou no aplicativo de celular, cujo passo principal é a confirmação de seu número de telefone móvel, o cliente (denominação da plataforma àquele que pretende contratar um profissional) é levado a uma página para "contratar um profissional". O cliente então deve escolher um serviço entre os diversos citados, como assistência técnica, reformas, aulas, moda e beleza, design e tecnologia, serviços domésticos, consultoria, saúde etc.

\footnotetext{
${ }^{4}$ A pesquisa teve a participação de todos os integrantes do grupo Trab21, em especial de Lívia Bená Alves e Bruna Miranda de Carvalho de Holanda, a quem agradecemos.
} 
Após explicitado qual tipo de profissional (ou serviço, a plataforma trata como sinônimos), a empresa encaminha o contato do cliente para diversos profissionais cadastrados a partir da região de atuação e tipo de serviço, para que, se desejarem, entrarem em contato para oferecimento de seus serviços e negociação das condições contratuais.

Um ponto é crucial de ressaltar logo de início em relação ao modus operandi da plataforma: apesar de a empresa informar o interesse do cliente para vários profissionais, somente três poderão acessar o candidato a tomador de serviços, e esses três trabalhadores serão aqueles que primeiro pagarem à plataforma "moedas" para o desbloqueio do contato do cliente (GETNINJAS, 2020a).

Assim dispõe o “Termo de Uso” (GETNINJAS, 2020):

5.1 No Modelo de Utilização de Moedas, os Contratantes prestarão informações básicas sobre os Serviços que pretendem contratar e os Orçamentos serão disponibilizados aos Prestadores que poderão, de livre vontade, escolher se terão acesso às informações de contato do Contratante.

5.2 Os dados de contato do Contratante somente serão disponibilizados ao Prestador após o desconto de um número pré-determinado de Moedas ("Moedas"), que poderão ser adquiridos pelo Prestador. (grifos não constantes no original).

No exemplo abaixo (figura 1), o trabalhador precisa de 59 "moedas" para desbloquear o contato do cliente. Além disso, há as informações sobre o serviço e é mostrado que um profissional já havia liberado o contato, faltando ainda duas vagas. 
Figura 1 - Captura de tela de celular em forma de imagem

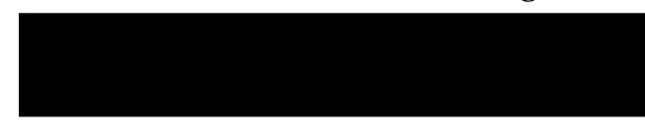

Invista em moedas e

negocie diretamente

com os clientes

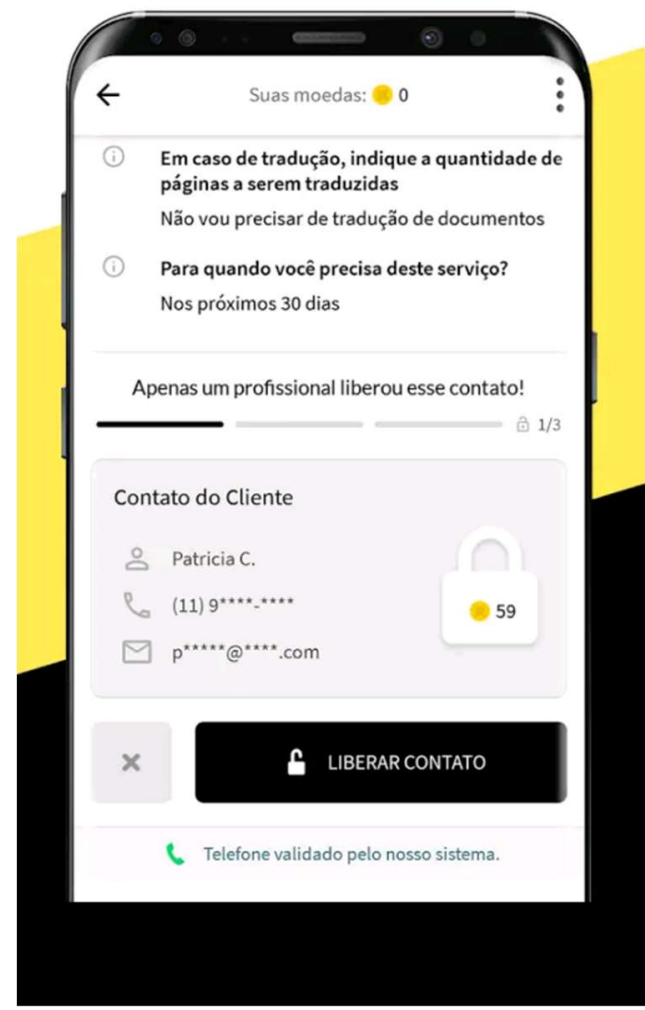

Fonte: Imagem fornecida pela GetNinjas na Play Store do Android (2019)

As "moedas" são uma espécie de dinheiro virtual que é vendido pela empresa, por meio de cartão de crédito ou de boleto bancário, como condição para que seja desbloqueado o contato do demandante de serviço. A empresa explica que "As moedas são como um dinheiro exclusivo do GetNinjas que o profissional investe para aceitar um pedido pelo aplicativo e então, desbloquear o contato do cliente." (grifo no original)

A empresa continua na explicação: “Através das moedas criamos um meio para poder fornecer autonomia para o profissional escolher os serviços." A empresa informa ainda que 1 moeda equivale a 0,15 centavos de real, que são vendidas por pacotes montados pela plataforma, mas a quantidade de moedas necessárias para obtenção do contato do cliente somente é descoberta quando a plataforma envia a proposta de serviço ao profissional, conforme a figura 1. Conforme os Termos de Uso da plataforma, no item 7.3, o preço a e disponibilidade das moedas podem ser 
alterados unilateralmente pela empresa "sem aviso prévio, podendo haver variação dinâmica baseada em fatores como local, tipo e oferta de orçamentos".

As "moedas", identificadas no site e no app com um círculo dourado, são desta forma imprescindíveis para que os profissionais sejam contratados. O serviço, no entanto, é totalmente gratuito para os tomadores de serviço.

A partir do momento em que o contato do cliente é desbloqueado, a plataforma não intervém na relação entre o cliente e o profissional, sendo a negociação e o possível fechamento do contrato, assim como o pagamento pelo serviço, realizados diretamente pelos interessados (GETNINJAS, 2020a). A plataforma não sabe nem mesmo se houve a contratação ou não do profissional. Após alguns dias do requerimento do serviço, os clientes recebem um e-mail perguntando como foi a busca pelo profissional:

Figura 2 - Captura de tela de celular em forma de imagem

\section{GetNinjas}

Conte-nos a sua experiência com o GetNinjas!

Alguns dias atrảs vocề fez um pedido de Profissionais de Gravação de

Vídeos e estamos ansiosos para saber se conseguimos te ajudar.

Você contratou um profissional pelo GetNinjas?

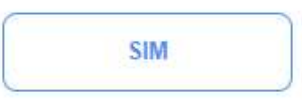

EM NEGOCIAÇÄO

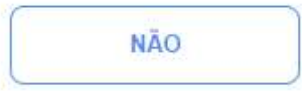

Fonte: GetNinjas (2019a)

Como usual nas plataformas, os trabalhadores podem ser avaliados pelos clientes. Porém, como o fechamento dos negócios não é realizado pela plataforma, ela não se imiscui na prestação dos serviços. Não há como buscar profissionais específicos a partir de suas avaliações e também não tem como se verificar as avaliações daqueles que são oferecidos aos clientes.

\subsection{O perfil dos trabalhadores da GetNinjas}

Apesar de terem sido respondidos 24 questionários, nem todos os trabalhadores responderam a todas as perguntas.

Dos respondentes, verifica-se que a maior faixa etária, 42,9\%, está entre 33 a 41 anos, sendo que de 25 a 41 anos temos mais de $70 \%$ dos profissionais (figura 3 ). 
Figura 3 - Faixa etária ${ }^{5}$

Qual sua idade?

21 responses

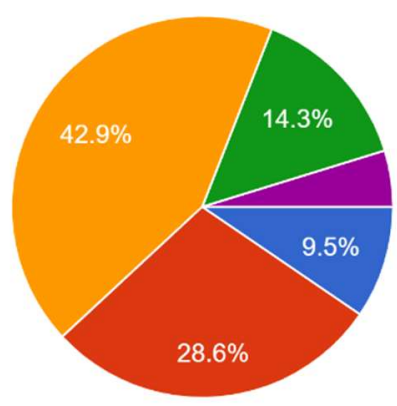

16 a 24 anos

25 a 32 anos

33 a 41 anos

42 a 50 anos

Acima de 50 anos

Fonte: Tabulação feita pelos autores.

Os trabalhadores ouvidos estavam espalhados por todo o Brasil, desde Brasília, passando por Curitiba, Goiânia, Belo Horizonte, Rio de Janeiro, sendo a maior parte sediada no Estado de São Paulo.

Quase a metade dos respondentes tem pelo menos curso superior completo, sendo que se contar com superior incompleto chega-se a $72,8 \%$ dos respondentes (figura 4).

Figura 4 - Escolaridade 6

\section{Formação educacional?}

22 responses

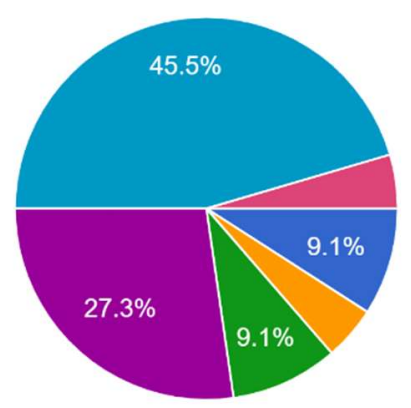

Ensino fundamental incompleto

Ensino fundamental completo

Ensino médio incompleto

Ensino médio completo

Superior incompleto

Superior completo

Mestrado

Fonte: Tabulação feita pelos autores.

\footnotetext{
${ }^{5}$ Gráfico gerado automaticamente pelo Formulários Google. Está oculto na imagem o percentual dos trabalhadores acima de 50 anos que responderam às perguntas, que corresponde a $4,8 \%$ do total.

${ }^{6}$ Gráfico gerado automaticamente pelo Formulários Google. Está oculto na imagem o percentual dos trabalhadores que possuem Mestrado e que responderam às perguntas, que corresponde a $4,5 \%$.
} 
Quase a totalidade já havia sido empregada (92,55\% - figura 5), desde as profissões de serviços gerais, vendedor ou eletricista a secretária executiva e cientista social. Os profissionais atuam na plataforma nos mais diversos serviços, como canto, shows musicais, fotografia, passando por maquiagem e consertos em geral. A maior parte deles utiliza outras plataformas como Instagram, casamento.com, 99 freelas, Facebook, Sem Patrão e Habitissimo.

Figura 5 - Experiência profissional ${ }^{7}$

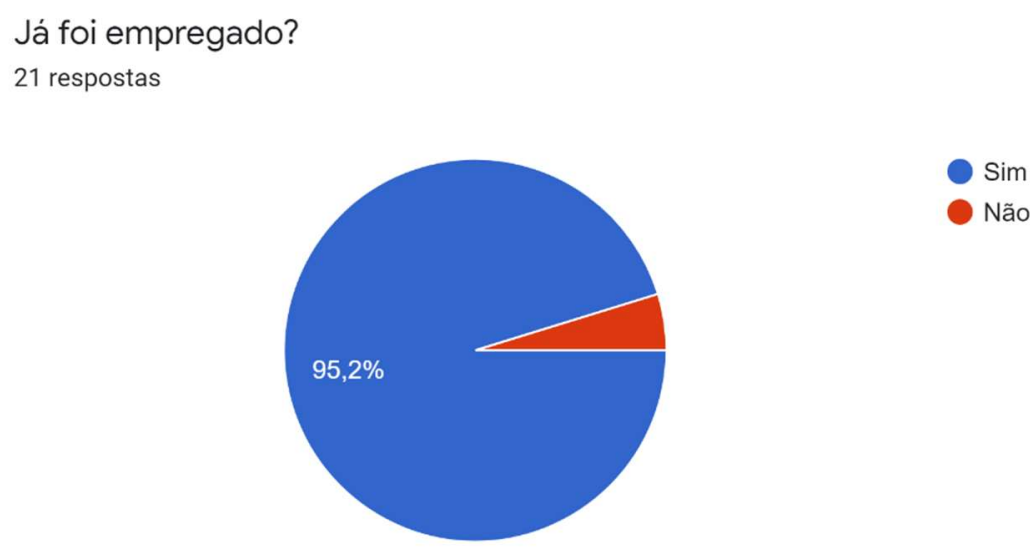

Fonte: Tabulação feita pelos autores.

Uma vez perguntados sobre o papel da plataforma, a maior parte dos trabalhadores citou "trazer clientes" e "unir esses aos profissionais da plataforma". Alguns ex-usuários chegaram a relatar que passaram pouco tempo na plataforma, o suficiente para servir "como meio de divulgar meus serviços em um local onde eu ainda não tinha uma rede de clientes".

Mais de um quarto dos entrevistados (28,6\%) informaram que a plataforma é sua única fonte de renda. A variação de tempo de trabalho na plataforma é muito grande, podendo ir de pessoas que nunca conseguiram trabalho na plataforma até quem trabalhe de segunda a sábado ou quase diariamente, não havendo uma prevalência.

Em relação às "moedas", a maior parte dos trabalhadores reclamou do seu valor, tendo adquirido pacotes da plataforma, indo de $\mathrm{R} \$ 79,90$ por 500 moedas, $\mathrm{R} \$$ 149,00 por 1000 moedas ou R $\$ 179,00$ por 1200 moedas. Três respondentes disseram que estavam desistindo pelo alto valor. Perguntados quanto que se gastava para a

\footnotetext{
${ }^{7}$ Gráfico gerado automaticamente pelo Formulários Google. Está oculto na imagem o percentual dos trabalhadores que não foram empregados e que responderam às perguntas, que corresponde a $4,8 \%$.
} 
obtenção de um contato de cliente, um trabalhador informou que "apostava" cerca de 110 moedas em média para cada possível cliente, três disseram que "depende" e outros apontaram de 47 a 50 moedas ou 79 moedas. Interessante notar que um dos respondentes afirmou que a quantidade de moedas necessárias dependia do aparelho celular do trabalhador.

Aqui está outro ponto que deve ser realçado: a estratégia de utilizar "moedas virtuais" para o desbloqueio de contatos é baseada na psicologia comportamental, que há muito tempo descobriu que a utilização de sistema de créditos ou dinheiro virtual, como o cartão de crédito, faz com que as pessoas gastem mais. É a mesma tática utilizada pelos videogames on-line e baseados em celular, supostamente grátis (MARDIGAN, 2016).

Outro ponto importante é que não é sem razão que uma "moeda" valha em torno de quinze centavos de real (ou que seu preço real oscile em razão de pacotes): isso também é estratégia da psicologia comportamental para que os trabalhadores não tenham noção de quanto estão gastando por conta de cada proposta de trabalho. Assim, comprando em moedas de valor opaco em cartão de crédito, aumentam-se as chances de os trabalhadores gastarem mais, por não terem noção de que estão gastando dinheiro real ou de quanto estão gastando para trabalhar.

A maioria dos trabalhadores informou que não há controle realizado pela plataforma. Alguns disseram que o controle se dá nas "recomendações" deixadas pelos clientes (18\%). Apesar disso, $81 \%$ dos respondentes davam importância máxima à avaliação do cliente (figura 6 ), sendo que $72,7 \%$ receavam obter uma má avaliação dos clientes (figura 7).

Figura 6 - Gráfico

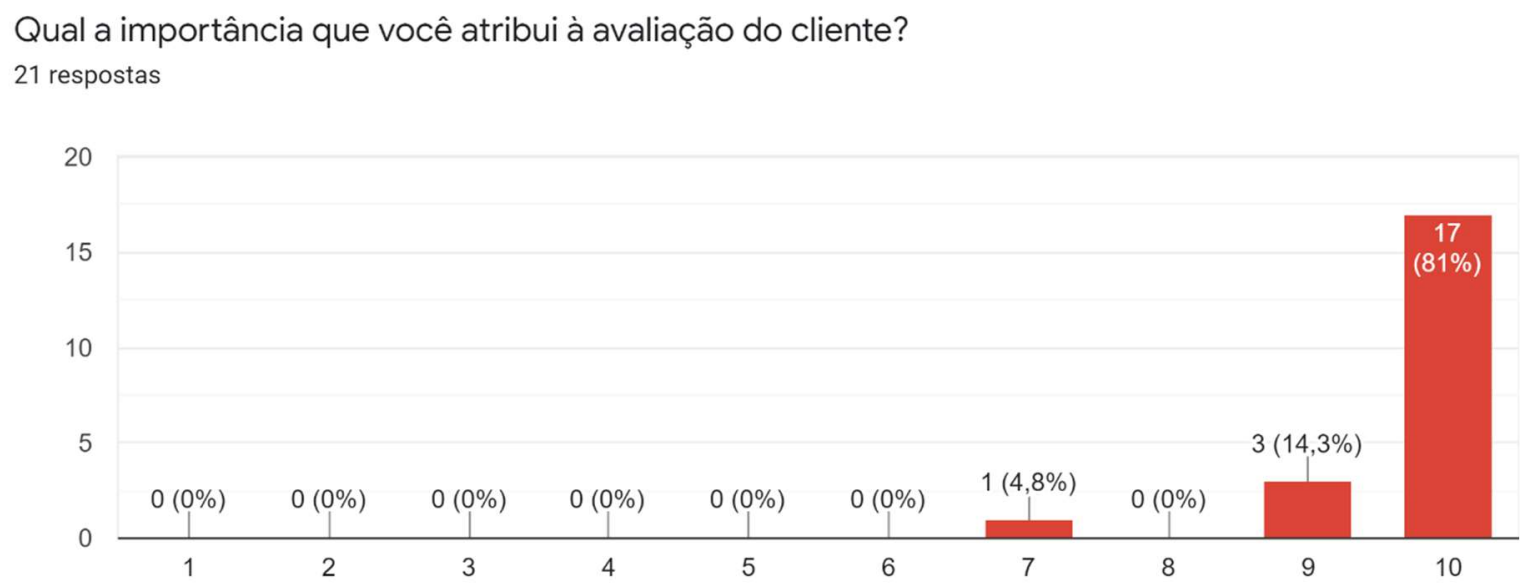

Fonte: Tabulação feita pelos autores. 
Figura 7 - Gráfico

Você receia obter uma má avaliação dos clientes?

22 respostas

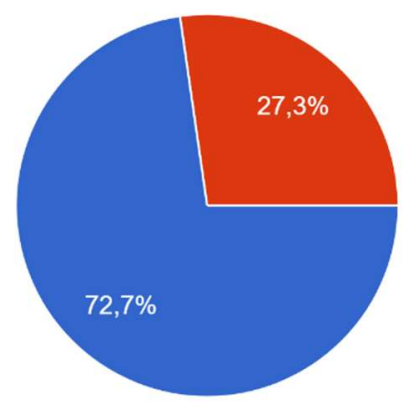

Sim
Não me importo

Fonte: Tabulação feita pelos autores.

Como condição sine qua non para usufruir dos serviços da plataforma, os trabalhadores aceitam e se submetem ao sistema de qualificação adotado por GetNinjas. São opiniões pessoais dos consumidores, mas que podem fazer com que a plataforma cancele, exclua ou suspenda por tempo indeterminado cadastros que apresentem qualificações negativas de forma reiterada.

Entretanto, a recíproca não é verdadeira. Alguns usuários se queixaram da dificuldade para se prevenir de consumidores maliciosos ("Clientes que solicitam serviço e quando mandamos mensagens elas nem respondem") e da ausência de contraditório antes da qualificação ("Não há um espaço de resposta de minha parte caso haja uma crítica por parte de um cliente que não tenha ficado satisfeito com meu trabalho").

Esse rebaixamento dos profissionais por meio de mensagens que ficam consignadas em suas páginas pessoais da plataforma vai de encontro com o disposto no artigo 29, $\S 4^{\circ}$ da Consolidação das Leis do Trabalho, que dispõe que: "É vedado ao empregador efetuar anotações desabonadoras à conduta do empregado em sua Carteira de Trabalho e Previdência Social" (BRASIL, 1943).

Tais avaliações são unilaterais e não têm a possibilidade de contraditório, além de terem o poder de macular a reputação do trabalhador por toda a sua trajetória profissional.

Em torno de $90 \%$ dos respondentes se considera um trabalhador autônomo (figura 8) e 27,3\% estavam à procura de emprego (figura 9). 
Figura 8 - Gráfico

Você se considera um autônomo?

22 respostas

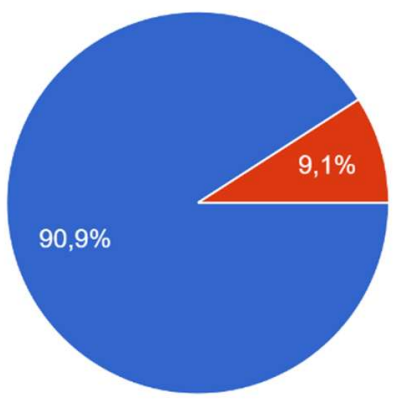

Você procura um emprego?

22 respostas

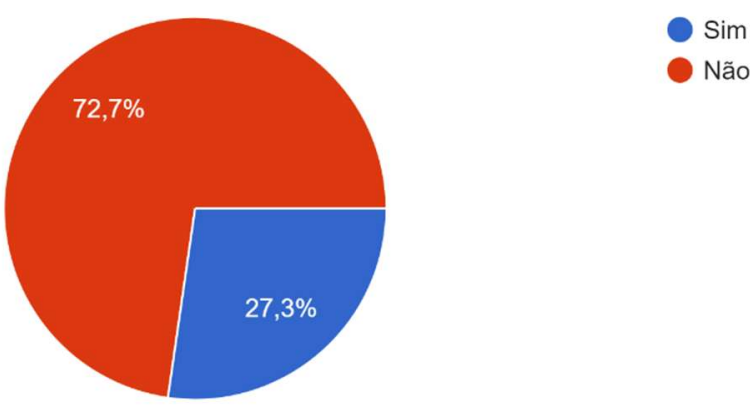

Fonte: Tabulação feita pelos autores.

Talvez essa baixa procura possa estar ligada a certa resignação acerca da realidade do desemprego no país. Segundo publicação recente do Instituto Brasileiro de Geografia e Estatística (IBGE, 2019), um contingente de 3,35 milhões de desempregados no país procura trabalho há pelo menos dois anos, e não há indicadores de que o cenário econômico vai mudar, ao menos em um curto prazo.

A instabilidade e a insegurança dessa realidade parecem conduzir a uma busca de alternativas desses trabalhadores para algum tipo de meio de subsistência que lhes garanta uma renda mínima enquanto os indicadores econômicos permanecem pessimistas. Até porque a mera busca por um emprego demanda gastos extras com 
o vestuário adequado, a depender da vaga que se almeja; com o deslocamento para entrega de currículos e entrevistas; com a atualização profissional, dentre outros investimentos que não estão ao alcance de muitas dessas pessoas que estão desempregadas há tanto tempo.

Quanto à avaliação em relação à plataforma, alguns trabalhadores apontaram como problema o fato de pagar moedas com clientes que solicitam os serviços e nem respondem as mensagens dos profissionais. $\mathrm{O}$ trabalhador $\mathrm{A}$ informou que "não há uma certeza de que quem te contratou realmente está procurando por um profissional ou se que (sic) apenas especular, o que faz com que gastemos moedas à toa".

O trabalhador B tem impressão similar:

Não há um espaço de resposta de minha parte caso haja uma crítica por parte de um cliente que não tenha ficado satisfeito com meu trabalho (caso que nunca aconteceu mas pode vir a acontecer)....... Não há esclarecimento ao cliente que nós, prestadores de serviços, pagamos para poder abrir um chamado, pois muitas vezes eles nem sequer respondem quando chamamos pelo WathApp (sic)...

O trabalhador $\mathrm{C}$ colocou assim suas queixas:

A ideia do GetNinjas é ótima porém os créditos altíssimos são um absurdo... Tanto GetNinjas ou Habitissimo ... Estamos migrando para jornais de bairro ou aplicativos gratuitos... O fato de o Cliente não pagar... perdemos muitos créditos por pessoas desinformada (sic) e que muitas vezes entra para apenas testar o aplicativo gratuitamente e muitos não fecham com ninguém do App e sim com indicações pessoais.

O trabalhador D informou outro problema relacionado às moedas: "Já realizei alguns trabalhos e foi bom. Minha área é a confeitaria é o valor de moedas mais alto para desbloquear um cliente. Tem que ser padrão para todos, pois o valor que nós pagamos é igual. Então seria justo dessa forma".

Um ponto importante foi levantado pelo trabalhador E: "Contra: Valor do serviço acaba sendo leiloado (mas isso é fruto da crise atual que desencadeia uma concorrência desleal de meus colegas)".

A questão do leilão inverso é importante, pois ela decorre do próprio desenho da plataforma, que coloca três trabalhadores em concorrência direta a cada oferta de trabalho, não sendo assim incidental, mas central na plataforma estudada. A cada oferta de trabalho o contratante pode ficar jogando com os três indicados, em um leilão negativo cujo limite estará somente na possibilidade de os trabalhadores recusarem o trabalho. 
A maior desvantagem apontada, contudo, refere-se à cobrança de certas tarifas, chamadas pela plataforma de "moedas", que são uma espécie de crédito que o trabalhador adquire do GetNinjas e depois lança mão para poder acessar os dados de seus eventuais contratantes.

\section{ClassifiCAÇÃO DA PLATAFORMA}

O Crowdsourcing consiste em uma espécie de prestação de serviço por um trabalhador, por meio de uma chamada ou convocatória, para serviços especializados ou não, em que há o envolvimento de outros dois elementos além do executante: o solicitante do serviço (empresa ou indivíduo); e a plataforma virtual, que faz a união das duas pontas desse negócio (marketplace) (TODOLÍ SIGNES, 2017).

Verifica-se que a plataforma realmente se comporta como um marketplace, pois simplesmente realiza a ligação entre cliente e tomador, não se imiscuindo em nada na prestação de serviços, bem ao contrário das plataformas de entrega de mercadorias e alimentação e de transporte de pessoas.

Adrián Todolí Signes (2017), que observa ao menos quatro tipos diferentes de negócios em relação às plataformas digitais de trabalho, conforme adiante explicitaremos: i) crowdsourcing on-line $\mathrm{x}$ crowdsourcing off-line; ii) crowdsourcing genérico x crowdsourcing específico (TODOLÍ SIGNES, 2017).

Por crowdsourcing on-line, Todolí Signes (2017) entende como as tarefas que podem ser realizadas em qualquer parte do mundo ("de forma global"), pois cumpridas por meio de ferramentas pertencentes ao ambiente completamente virtual, em que trabalhadores de qualquer parte do mundo podem se oferecer para executá-las. É o caso de um dos entrevistados, que presta serviços de tradução e confecção de textos para empresas.

Já o crowdsourcing off-line depende de um trabalho físico para ser executado, atraindo a prestação do serviço para um ambiente local, o que leva o trabalhador a se deslocar para o local desejado, como no caso das maquiadoras que responderam às perguntas da pesquisa.

Não obstante, devemos tomar o cuidado de ponderar que não existe prestação de serviço que se dê on-line, pois todo labor humano é prestado no que podemos chamar de "vida real" (off-line), ao menos até que a realidade ora adstrita aos filmes de ficção científica se imponha em nossas vidas (OLIVEIRA, CARELLI, GRILLO, 2020).

O trabalho que importa à regulação não é aquele realizado por bots dentro de um ambiente virtual, mas sim aquele prestado por seres humanos, que é sempre off-line, mesmo o trabalho realizado por pessoas diretamente em uma plataforma, como programação de softwares ou etiquetação de imagens.

Essas pessoas são de carne e osso e realizam o trabalho com o esforço físico e mental próprios da vida material e suas necessidades de ordem real, como se alimentar, descansar, divertir e se relacionar. Há de se questionar inclusive o rótulo 
hoje expandido de "trabalhador digital", pois acaba por desvirtuar o entendimento da realidade das pessoas e de suas necessidades.

Talvez uma nomenclatura mais técnica seria "trabalho executado de forma global" em relação a "trabalho executado de forma local", e que parece demonstrar de forma mais acurada o que Todolí Signes (2017) adota como critério para essa classificação. Essa é a denominação utilizada por Antonio Aloisi e Valerio De Stefano (2018), conforme o quadro adaptado a seguir (figura 10):

Figura 10 - Esquema de classificação de trabalho baseado em plataforma

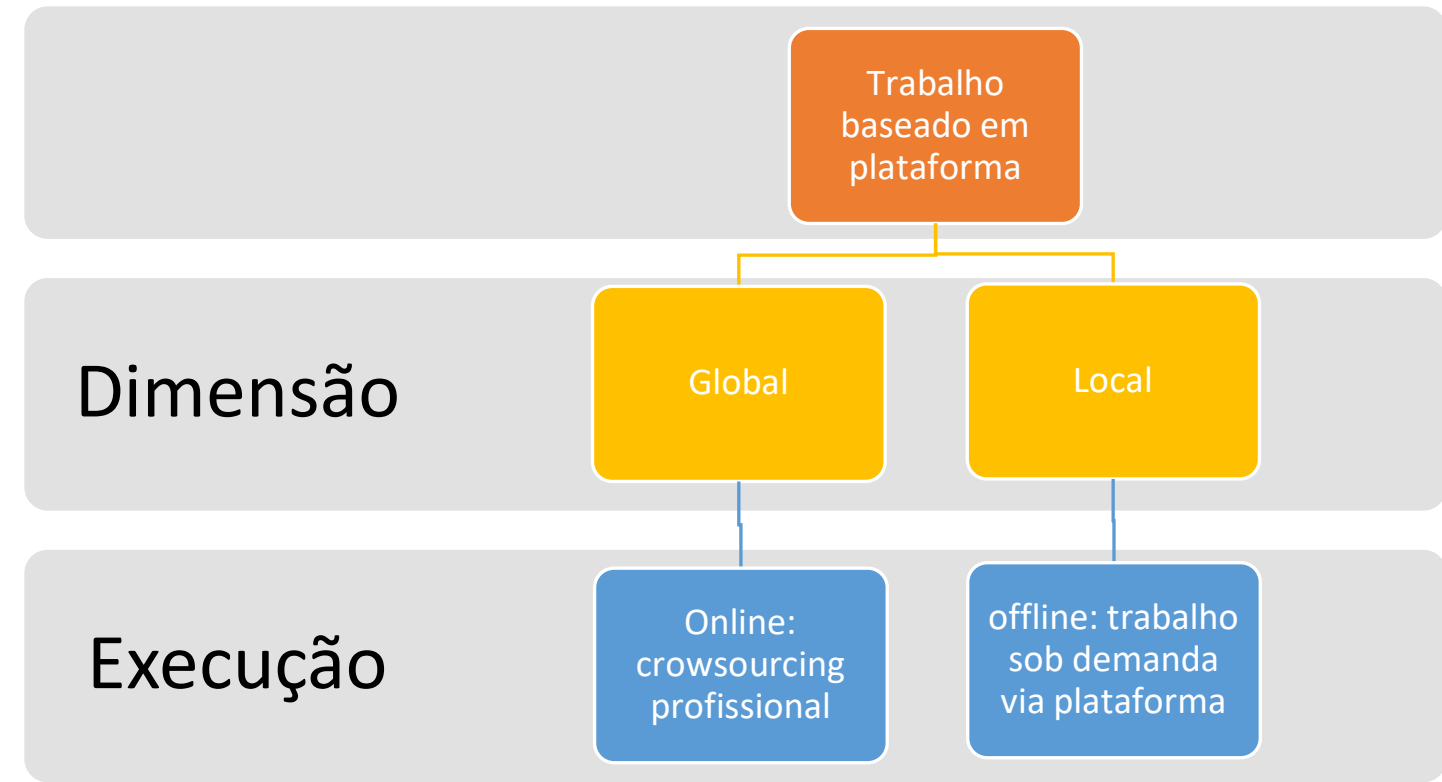

Fonte: Antonio Aloisi e Valerio De Stefano (2018)

Assim, apesar de manter a diferença entre "online" e "off-line" para a execução do trabalho, a taxinomia de Aloisi e De Stefano (2018) leva em conta principalmente a dimensão que o trabalho alcança em relação à oferta da multidão de trabalhadores.

Voltando à classificação apresentada por Todolí Signes (2017), há plataformas em que os solicitantes podem demandar qualquer tipo de trabalho (crowdsourcing genérico), e há aquelas em que os clientes podem buscar serviços específicos de um setor de atividade (crowdsourcing específico).

Conforme vimos, diferentes atividades podem ser prestadas por meio do GetNinjas, pelo que concluímos que se trata de uma plataforma genérica. Como exemplos de crowdsourcing específico Todolí Signes aponta plataformas de professores particulares e de cozinheiros a domicílio. Dado seu caráter bem mais segmentado, este último caso possibilita, em regra, um maior controle da plataforma sobre o modo de execução do serviço do que no caso de crowdsourcing genérico. 
Assim, considerando a referida classificação, podemos afirmar que a plataforma GetNinjas é uma espécie de i) crowdsourcing misto (porque pode ser executado tanto off-line quanto on-line) e ii) genérico.

\section{A ILEGAlidADE DA COBRANÇA DOS TRABALHADORES}

Percebe-se claramente a estratégia da plataforma de obter todo o seu ganho em cima da concorrência dos trabalhadores entre si pelas ofertas de trabalho. Não há qualquer cobrança dos contratantes, somente recaindo sobre os ofertantes de trabalho.

O Tratado de Versalhes, documento que é considerado o marco da internacionalização do Direito do Trabalho, estabeleceu em seu art. 427 o princípio fundamental segundo o qual "o trabalho não há de ser considerado como mercadoria ou artigo de comércio" (LIGA DAS NAÇÕES, 1919).

Este postulado foi incorporado posteriormente pela Organização Internacional do Trabalho, que o incluiu na chamada "Declaração de Filadélfia", a qual estabeleceu os fins e objetivos daquela organização internacional (OIT, 1944), e significa que o trabalho não pode ser tratado como um bem meramente econômico, sujeito às leis de oferta e demanda, vedando-se, por conseguinte, que seja objeto de livre estipulação pelas partes. Isto é, há de ser observado um conteúdo mínimo de limitações à alienação do trabalho, na medida em que se reconhece que as transações entre o capitalista e o trabalhador não podem dispor livremente sobre padrões que assegurem a dignidade da pessoa humana.

Outra dimensão desse princípio é que o trabalho não pode ser comprado, ou seja, não podem ser vendidas oportunidades ou postos de trabalho. O objetivo dessa regra é bem claro: evitar que os postos e possibilidades de trabalho fiquem com aqueles que detenham melhores condições financeiras, e que os que não tenham recursos não sejam alijados da busca por trabalho, perpetuando um ciclo vicioso de pobreza e de desigualdade social.

Nesse contexto, a Convenção 181 da OIT, que regula a atividade das agências privadas de emprego, para cumprir esse princípio assim dispõe:

Artigo $7^{0}$

1 - As agências de emprego privadas não devem impor aos trabalhadores, direta ou indiretamente, no todo ou em parte, $o$ pagamento de honorários ou outros encargos.

Artigo $1^{\circ}$

1- Para os efeitos da presente Convenção, a expressão «agência de emprego privada» designa qualquer pessoa singular ou coletiva, independente das autoridades públicas, que preste um ou mais dos seguintes serviços referentes ao mercado de trabalho:

a) Serviços que visam a aproximação entre ofertas e procuras de emprego, sem que a agência de emprego privada se torne parte nas relações de 
trabalho que daí possam decorrer; (grifos não constantes no original) (OIT, 1997).

O que o GetNinjas faz é exatamente a "aproximação entre ofertas e procuras de empregos", como declarou no seu termo de uso ${ }^{8}$ : "1.1.3 Viabilizar o contato direto entre Prestadores e Contratantes interessados em adquirir os Serviços, por meio da divulgação das informações de contato de uma parte à outra" Assim, sua natureza é indubitavelmente uma agência de emprego privada, e a cobrança de qualquer encargo ou honorário não pode ser aceita.

Tal convenção não foi ainda ratificada pelo Brasil. Entretanto, não há regulação específica para agências de emprego que realizam somente o trabalho de aproximação e oferta de trabalho no Brasil, aplicando-se o direito comparado, conforme dispõe o art. $8^{0}$ da Consolidação das Leis do Trabalho, conforme enunciado aprovado na $1^{\mathrm{a}}$ Jornada de Direito Material e Processual na Justiça do Trabalho:

3. Fontes do direito - Normas Internacionais. I - Fontes do direito do trabalho. Direito comparado. Convenções da OIT não ratificadas pelo Brasil. O Direito Comparado, segundo o art. 80 da Consolidação das Leis do Trabalho, é fonte subsidiária do Direito do Trabalho. Assim, as Convenções da Organização Internacional do Trabalho não ratificadas pelo Brasil podem ser aplicadas como fontes do direito do trabalho, caso não haja norma de direito interno pátrio regulando a matéria. (ANAMATRA, 2008).

Essa interpretação coaduna com o disposto na Lei nº 6.019/1974, em seu art. 18, que tratando de intermediação de mão de obra, afirma que é "vedado à empresa de trabalho temporário cobrar do trabalhador qualquer importância, mesmo a título de mediação, podendo apenas efetuar os descontos previstos em Lei" (BRASIL, 1974).

Assim, pela aplicação do princípio da não-mercantilização do trabalho, da Convenção $n^{-0} 181$ da Organização Internacional do Trabalho e, por analogia, do art. 18 da Lei no 6.019/1974, não é legal a cobrança de valores de trabalhadores para a prestação de serviços de intermediação e aproximação entre trabalhadores e ofertas de trabalho, mesmo que disfarçadas de "moedas virtuais".

\section{CONCLUSÕES}

As profundas mudanças que atingem em cheio o mundo do trabalho, decorrentes, como vimos, do surgimento de novas tecnologias, têm tirado o foco da figura do trabalhador empregado, sujeito típico do manto protetivo do Direito do Trabalho, para abrir espaço a outras formas aparentes de prestação de labor

${ }_{8}^{8}$ Disponível em https://www.getninjas.com.br/termos-de-uso. Acesso em: 08 jan. 2020. 
humano, que para alguns autores são em determinados casos consideradas meras reformulações de práticas antigas de exploração (CARELLI, 2019). No trabalho em plataforma há tanto a continuidade da burla da relação de emprego pela criação de uma nova figura de intermediador, como em outras ocasiões, a exemplo do caso aqui estudado, ocorre a continuidade da situação histórica do mercado de trabalho brasileiro que se baseia em grande parte no trabalho informal, ou no "bico", sem direitos e baixa remuneração, porém com acirrada concorrência.

Uma das marcas dessa nova (velha) realidade é a profunda concorrência entre trabalhadores, que se entendem autônomos, e que aparentemente querem permanecer assim.

Destaca Todolí Signes (2017) que esse novo tipo de trabalho coloca os trabalhadores numa espécie de leilão em que a oferta é muito alta, e só há espaço para aqueles que estiverem dispostos a receber pelo menor preço. Assim, trata-se de um leilão negativo: quem der menos valor a si mesmo leva o trabalho. Ademais, no caso da plataforma de trabalho global, a competição também envolve disputa de leis trabalhistas, em que trabalhadores oriundos de países mais protetores teriam uma desvantagem competitiva, numa realidade bem próxima daquela de "mercado de leis" (law shopping) apresentada por Alain Supiot (2017).

A vulnerabilidade do trabalhador de plataformas mostrou-se patente quando da análise das respostas dos entrevistados. Trata-se de uma forma de labor que, comparada à tradicional figura do empregado subordinado, encontra-se desamparada e sujeita à desigualdade de poder com relação à plataforma e também em relação aos clientes, cabendo ao prestador do serviço rejeitar as condições impostas, dentro de um contexto de dificuldade de acesso ao mercado formal de trabalho, ou a elas se sujeitar.

Outra vulnerabilidade apontada é a possibilidade de deixar avaliações negativas aos trabalhadores, que poderão macular a sua vida profissional, o que contraria a lei brasileira.

Em relação à cobrança dos trabalhadores, que acirra ainda mais a concorrência, percebe-se que é prática ilegal e atenta contra os princípios mais basilares da Organização Internacional do Trabalho.

Por fim, as características do caso em exame neste artigo ressaltam a necessidade premente da realização de estudos de todas essas novas configurações do trabalho, que apresentam inegáveis desafios à proteção dos trabalhadores.

\section{REFERÊNCIAS}

ABILIO, Ludmila Costhek. Uberização: Do empreendedorismo para o autogerenciamento subordinado. Psicoperspectivas, Valparaíso, v. 18, n. 3, p. 4151, nov. 2019. ISSN 0718-6924 versão online. Disponível em 
$<$ https://scielo.conicyt.cl/scielo.php?script=sci_arttext\&pid=S071869242019000300041\&lng=pt\&nrm=iso>. Acesso em: 30 abr. 2020.

ALOISI, Antonio. Commoditized Workers. Case Study Research on Labour Law Issues Arising from a Set of 'On-Demand/Gig Economy Platforms. Comparative Labor Law \& Policy Journal, v. 37, n. 3, 1 may 2016. Disponível em <SSRN: https://ssrn.com/abstract=2637485> ou <http://dx.doi.org/10.2139/ssrn.2637485>. Acesso em: 30 abr. 2020.

ALOISI, Antonio; DE STEFANO, Valerio. European Legal framework for digital labour platforms. Luxembourg: European Commission, 2018. ISBN 978-92-7994131-3. Disponível em < https://publications.jrc.ec.europa.eu/repository/bitstream/JRC112243/jrc112243_le gal_framework_digital_labour_platforms_final.pdf >. Acesso em: 30 abr. 2020.

ANAMATRA. 1a Jornada de Direito Material e Processual na Justiça do Trabalho. São Paulo: LTr, 2008. ISBN: 9788536111353.

BRASIL. Decreto-Lei n. 5.452, de 1ํ de maio de 1943. Aprova a Consolidação das Leis do Trabalho. Diário Oficial [dos] Estados Unidos do Brasil: secção 1, Rio de Janeiro, DF, ano 82, n. 184, p. 11937-11984, 9 ago. 1943.

BRASIL. Lei no 6.019, de 3 de janeiro de 1974. Diário Oficial da União: seção 1, p. 73, 4 jan. 1974.

CARELLI, Rodrigo de Lacerda. Trabalho na Uber é neofeudal, diz estudo. "São empreendedores de si mesmo proletarizados". [Entrevista cedida a] Marco Weissheimer. Sul21, Porto Alegre, 13 mai. 2019. Disponível em: < https://www.sul21.com.br/areazero/2019/05/trabalho-na-uber-e-neofeudal-dizestudo-sao-empreendedores-de-si-mesmo-proletarizados/>. Acesso em: $30 \mathrm{abr}$. 2020.

CARELLI, Rodrigo de Lacerda; CASAGRANDE, Cássio Luís; OITAVEN, Juliana Carreiro Corbal. Empresas de transporte, plataformas digitais e a relação de emprego: um estudo do trabalho subordinado sob aplicativos. Brasília: Ministério Público do Trabalho, 2018.

DANIGNO, Emanuele. Labour and Labour Law in the time of the on-demand economy. Revista Derecho Social y Empresa, España, n. 6 (ejemplar dedicado a: Nuevas formas de trabajo. Retos presentes y futuros), p. 43-65, 2016. Disponível em: <https://www.dykinson.com/revistas/revista-derecho-social-y-empresa/760/>. Acesso em 30 abr. 2020. 
DUBAL, Veena. Wage Slave or Entrepreneur?: Contesting the Dualism of Legal Worker Identities. California Law Review, v. 105, p. 101-159, 2017.

GETNINJAS. GetNinjas: Encontre Profissionais ou Serviços, 2019. Disponível em:

$<$ https://play.google.com/store/apps/details?id=br.com.getninjas.pro\&hl=pt_BR>. Acesso em 30 abr. 2020.

GETNINJAS. Como foi sua procura por Profissionais de Gravação de Vídeos no GetNinjas? [mensagem pessoal]. Mensagem recebida por

<rodrigolcarelli@gmail.com> em 21 jun. 2019.

GETNINJAS. Termos e condições gerais de uso do site, 2020. Disponível em: <https://www.getninjas.com.br/termos-de-uso>. Acesso em 30 abr. 2020.

GETNINJAS. Como funciona o GetNinjas?, 2020a. Disponível em: $<$ https://help.getninjas.com/hc/pt-br/articles/360000327894-Como-funciona-oGetNinjas->. Acesso em: 30 abr. 2020.

IBGE. Pesquisa Nacional por Amostra de Domicílios Contínua (PNAD), ago. 2019. Disponível em:

<https://biblioteca.ibge.gov.br/visualizacao/periodicos/2421/pnact_2019_2tri.pdf >. Acesso em: 30 abr. 2020.

IVANOVA, Mirela et al. The App as a Boss? Control and Autonomy in Application-Based Management. Arbeit I Grenze I Fluss - Work in Progress interdisziplinärer Arbeitsforschung, n. 2, Frankfurt (Oder): Viadrina, 2018. DOI: doi:10.11584/Arbeit-Grenze-Fluss.2.

KALIL, Renan Bernardi. Capitalismo de plataforma e Direito do Trabalho: crowdwork e trabalho sob demanda por meio de aplicativos. Orientador: Otavio Pinto e Silva. Tese (Doutorado em Direito) - Faculdade de Direito, Universidade de São Paulo, São Paulo, 2019.

LIGA DAS NAÇÕES. Tratado de Versalhes, 1919. Disponível em: <https://www.un.org/unispal/document/auto-insert-199451/ >. Acesso em: 30 abr. 2020.

MARDIGAN, Jamie. Getting gamers: the psychology of vídeo games and their impact on the people who play them. Lanham: Rowman and Littlefield, 2016. 
OLIVEIRA, Murilo Carvalho Sampaio. O Direito do Trabalho (des)conectado nas plataformas digitais. Teoria Jurídica Contemporânea, v. 4, n. 1, 2019, p. 246-266.

OLIVEIRA, Murilo Carvalho Sampaio; CARELLI, Rodrigo de Lacerda; GRILLO. Conceito e crítica das plataformas digitais. Direito e Práxis, v. 11, n. 4, 2020, p. 2609-2634.

OIT. Constituição da Organização Internacional do Trabalho (OIT) e seu anexo (Declaração de Filadélfia), 1944. Disponível em:

<https://www.ilo.org/wcmsp5/groups/public/---americas/---ro-lima/---ilobrasilia/documents/genericdocument/wcms_336957.pdf $>$. Acesso em: 30 abr. 2020.

\section{OIT. Convenção 181 (Convenção Relativa às Agências de Emprego Privadas),} 1997. Disponível em:

<https://www.ilo.org/brasilia/convencoes/WCMS_242713/lang--pt/index.htm>. Acesso em: 30 abr. 2020.

TODOLÍ SIGNES, Adrián. O Mercado de Trabalho no Século XXI: on-demand economy, crowdsourcing e outras formas de descentralização produtiva que atomizam o mercado de trabalho. In: LEME, Ana Carolina Reis Paes; RODRIGUES, Bruno Alves; CHAVES JUNIOR, José Eduardo De Resende (coord.). Tecnologias disruptivas e a exploração do trabalho humano. São Paulo: LTr, 2017.

SUPIOT, Alain. Governance by Numbers: The Making of a Legal Model of Allegiance. Oxford/Portland: Hart, 2017, p. 167-282. 